\title{
Article
}

\section{Ion Exchange Resins for Condensate Polishing}

\section{StephenW. NAJMY}

Liquid Separations, The Dow Chemical Company, Larkin Laboratory, 1691 N. Swede Rd., Midland, Michigan, 48674 U.S.A.

\section{Naoki BESSHO}

Liquid Separations, Dow Chemical Japan Limited, Gotemba Laboratory, 92-2 Ogurano, Gotemba-shi, Shizuoka 412-0013 Japan

(Manuscript submitted February 15, 2003; accepted April 11, 2003)

\begin{abstract}
Various types of Condensate Polishing Grade resins with uniform particle size (UPS) are available from us since the first product of UPS resins was developed in 1983. Recently high cross-linked (XL) strong acid cation gel resins with UPS have been developed based on the requirements from nuclear power industry. A $12 \% \mathrm{XL}$ resin with $550 \mu \mathrm{m}$ diameter was installed at three boiling water reactor (BWR) and one pressurized water reactor (PWR) plants in the U.S. and a $14 \% \mathrm{XL}$ resin with $650 \mu \mathrm{m}$ diameter was installed at two BWR plants in Japan. Those resins have been working well with excellent performance. Our recent field experiences in the U.S. and Japan including the high XL resins are summarized in this paper.
\end{abstract}

\section{Introduction}

Deep bed condensate polishing with ion exchange resin is a critical process for both one-through type fossil power and nuclear power plants. The purpose of the ion exchange resin is to filter insoluble iron (crud) and to remove dissolved ionic impurities that inadvertently enter the steam cycle from condenser coolant inleakage, such as seawater or brackish water. The cleanliness of the feed water is essential for corrosion minimization, such as intergranular stress corrosion cracking (IGSCC) and intergranular attack (IGA) of the internal components of the nuclear reactor and steam generator (SG) systems.

Ion exchange resin products are manufactured to meet specific requirements related to their physical and chemical properties. In some cases the resin must also meet performance type specifications as measured by a laboratory test method that simulates the conditions of the full-scale application. Table 1 provides a list of uniform particle size (UPS) ion exchange resins offered by the Dow Chemical Company along with some of the key property specifications. Excellent uniformity of the DOWEX UPS resins without screening in the manufacturing process brings about exceptional kinetic properties, such as longer operating capacity to a conductivity breakthrough and faster rinsedown following a chemical regeneration or an external ultrasonic cleaning. These performance characteristics, together with superior mechanical strength, high resistance to osmotic shock and negligible fines generation due to attrition are all important considerations in the selection process of an ion exchange mixed resin for use in high purity condensate polishing. Many installations in the U.S. and in Japan utilize some of the resin 
products shown in Table 1 . The newest of these resin products are the $12 \%$ cross-linked (XI) and $14 \%$ XL cation gel resins. These resins were developed to address specific requirements from nuclear power stations in the U.S. and Japan, respectively. Key performance data from some of the full-scale field operations of these two high cross-linked cation resins are summarized here in this paper as new information or as an update to that reported previously.[1,2]

Table 1 DOWEX* Ion Exchange Resins with Uniform Particle Size for Condensate Polishing

\begin{tabular}{|c|c|c|c|c|c|c|c|}
\hline \multirow[t]{2}{*}{ Resins } & \multirow[t]{2}{*}{ Matrix } & \multicolumn{2}{|c|}{ TEC $[$ eq1/] } & \multicolumn{2}{|c|}{ WRC [\%] } & \multicolumn{2}{|c|}{$\mathrm{VMD}[\mu \mathrm{m}]$} \\
\hline & & spec. & ave. & spec. & ave. & spec. & ave. \\
\hline \multicolumn{8}{|l|}{ Cation Exchange Resins } \\
\hline DOWEX MONOSPHERE* $650 \mathrm{C}(\mathrm{H})$ & $10 \% \mathrm{XL}-\mathrm{Gel}$ & 2.0 & 2.09 & $46-51$ & 49.0 & $650 \pm 50$ & 665 \\
\hline DOWEX MONOSPHERE 575C NG (H) & $12 \% \mathrm{XL}-\mathrm{Gel}$ & 2.15 & 2.31 & $41-46$ & 44.5 & $550 \pm 50$ & 542 \\
\hline DOWEX MONOSPHERE 650HXC NG (H) & $14 \% \mathrm{XL}-\mathrm{Gel}$ & 2.2 & 2.40 & $39-44$ & 41.3 & $650 \pm 50$ & 667 \\
\hline DOWEX MONOSPHERE 750C $(\mathrm{H})$ & $10 \% \mathrm{XL}-\mathrm{Gel}$ & 1.9 & 2.07 & $46-51$ & 48.3 & $765 \pm 25$ & 770 \\
\hline DOWEX MONOSPHERE MP-525C $(\mathrm{H})$ & Macroporous & 1.6 & 1.75 & $50-54$ & 53.3 & $500 \pm 50$ & 504 \\
\hline \multicolumn{8}{|l|}{ Anion Exchange Resins } \\
\hline DOWEX MONOSPHERE 550A (OH) & Gel & 1.1 & 1.17 & $55-65$ & 60.7 & $590 \pm 50$ & 589 \\
\hline DOWEX MONOSPHERE 700A (OH) & Gel & 1.1 & 1.1 & $55-65$ & 60 & $700 \pm 50$ & 690 \\
\hline DOWEX MONOSPHERE MP-725A (OH) & Macroporous & 0.8 & 0.9 & $65-75$ & 70 & $690 \pm 50$ & 700 \\
\hline
\end{tabular}

XL : Crosslinkage, TEC : Total Exchange Capacity, WRC : Water Retention Capacity, VMD : Volume Median

Diameter * Trademarks of The Dow Chemical Company

\section{Development of High Cross-linked Cation Gel Resins}

Some BWR nuclear power plants are equipped with pre-filter systems upstream of the deep-bed condensate polishers. For these plants, a non-precoated filter, either cartridge or hollow fibers design, with full-flow operation removes insoluble iron to around $99 \%$ efficiency. For BWR nuclear power plants without upstream pre-filters the filtration of insoluble iron is an important role of the deep-bed condensate polisher. Poor control of feed water iron is a critical issue because excessive amounts of insoluble iron in the feed water can cause two major concerns:

- Heat transfer reduction - Iron buildup on the cladding of the nuclear fuel reduces heat transfer efficiency and can lead to nuclear fuel cladding failures.

- Shutdown dose rates - Non-optimal feedwater iron concentrations affect the transport of activated corrosion products, causing an increase in radiation dose rate on the reactor piping and increasing worker exposure.

In addition, the accumulation of insoluble iron deposits in combination with contaminant ions creates conditions conducive to IGSCC in pressure vessels and reactor internals.

Another chemistry control issue in BWR primary cycles is reactor water sulfate control and minimization. To this day, many stations still report contributions to reactor water sulfate from one or more of the following sources:

- Ionic sulfate not removed by the condensate polisher resin during conditions of condenser inleakage

- Ionic and organically-bound sulfate (post-UV) in the effluent streams of the condensate polisher and reactor water clean-up vessels

- Cation exchange resin fines that are sufficiently small to pass through the screened under-drain laterals of the condensate polisher vessels

For many BWR plants, sulfate in the reactor water is mostly sourced from polystyrene sulfonic acid leachables derived from cation resins in the either the deep-bed condensate polisher or the precoated filters. The cation resin 
types historically used for this application has been either an $8 \% \mathrm{XL}$ cation gel resin such as DOWEX HCR-W2 (H) or a $10 \% \mathrm{XL}$ cation gel resin such as DOWEX HGR-W2 (H). And although anion resins in the mixed bed will readily adsorb any sulfate and/or organic leachables with low molecular weight (MW), problems can occur with high MW organic leachables from cation resin. Previous studies suggest irreversible adsorption and surface kinetic impairment of anion resin due to the presence of organic leachables with molecular weights greater than 7000 . And with surface kinetic impairment of anion resin, the mixed bed condensate polishers do not perform as well during conditions of condenser in-leakage. Consequently, an increased oxidative stability and a reduced organic leachables rate were desired for the next generation cation resins.

In secondary cycle PWR condensate polishing, the residual regenerant is a potential source of sulfate in the downstream steam generator. This is especially true for PWR plants in the U.S. since the common practice is to regenerate the cation resin with sulfuric acid. Even still, higher cross-linked cation resins with improved oxidative stability and organic leachable characteristics may have some real merit in regenerable condensate polishing applications as well.

Another issue with mixed bed condensate polishers is the potential for resin classification during the hydraulic transfer of the resins to the service vessel. Since cation resins are denser than anion resins, a cation resin "heel" can form at the bottom of the service vessel. Without the capability to remix the resin, sulfate species that leach from the cation resin will carry downstream and concentrate in the reactor water (BWR primary cycles) or the steam generator (PWR secondary cycles) water. Therefore, a cation resin with a lower terminal settling velocity (TSV) compared to the $10 \% \mathrm{XL}$ standard size cation gel resin was desired. This was the reason for the smaller diameter design - to achieve a mixed resin combination with reduced-separability.

A specific consideration for nuclear power plants in Japan is that ion exchange resins are used for a relatively long time before their replacement - currently resins are used for approximately 10 years at BWR plants and for 4 years or more at PWR plants. Because storage space for waste resins is very limited, longer operating capacity (breakthrough capacity) and longer resin life were desired for the next generation cation resins.

In the U.S. today the $12 \%$ small diameter cation resin is the preferred cation resin in combination with DOWEX SBR-C $(\mathrm{OH})$ gaussian anion gel resin for use in BWR plants that operate without pre-filters. Although this is a less-separable combination, the common practice is to separate a portion of the anion resin from the mixed resin during the resin cleaning operation. This anion resin is the first transfer back to the service vessel to create an anion resin underlay. This underlay of anion resin at the bottom of the service vessels effectively improves reactor water sulfate control. With the underlay of anion resin, the less-separable mixed bed resin is working well at three BWR plants.

On the other hand, the combination of the $14 \%$ cross-linked standard-size UPS cation gel resin and a standard-size UPS anion gel resin was chosen for BWR and PWR plants in Japan. This high cross-link cation resin was developed jointly with Ebara Corporation in Japan. Filtration and reduced-separability of cation resin were not highly prioritized and the focus was placed on the stability of the cation resin against oxidation so as to minimize the amount of organic leachables. Based on our studies for TOC leaching characteristics, mixed bed kinetics and regeneration efficiency, the $14 \% \mathrm{XL}$ was chosen as the optimal XL resin for condensate polishing applications in Japan and installed at two BWR plants. An in-plant column test has been successfully completed at a PWR plant and also the resin has been proposed to the PWR plant.

\section{$312 \%$ XL Cation Gel Resin in Less-Separable Mixed Bed at BWR plants in U.S.}

The Pilgrim Nuclear Power Station of Entergy (Massachusetts) experienced difficulty in controlling reactor 
water sulfate. Levels ranged between 1 and $3 \mu \mathrm{g} / \mathrm{dm}^{3}$ with periodic excursions up to $4 \mu \mathrm{g} / \mathrm{dm}^{3}$ and higher. The plant replaced all seven beds with the less-separable mixed resin in their condensate polisher vessels - the fall of 2000 for the first three beds and the spring of 2001 for the remaining four beds. In addition, the resin-transfer procedures incorporated an anion resin underlay, and the station installed new under-drain laterals. These new laterals were constructed with a higher strength design to alleviate pressure drop issues and improve resin transfer capability.

The impact of the new resin beds on reactor water sulfate and feed water iron controls are illustrated by Fig. 1 and 2 respectively. Since the replacement, the reactor water sulfate and the feed water iron control have improved and remain steady in the range of $0.5-1 \mu \mathrm{g} / \mathrm{dm}^{3}$ of sulfate and in the range of $1-2 \mu \mathrm{g} / \mathrm{dm}^{3}$ of iron.

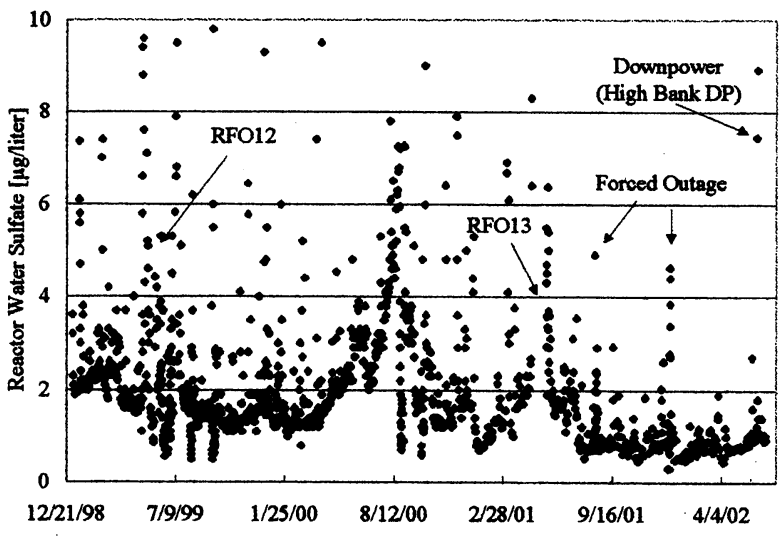

Fig. 1 Reactor Water Sulfate Control at Pilgrim Plant

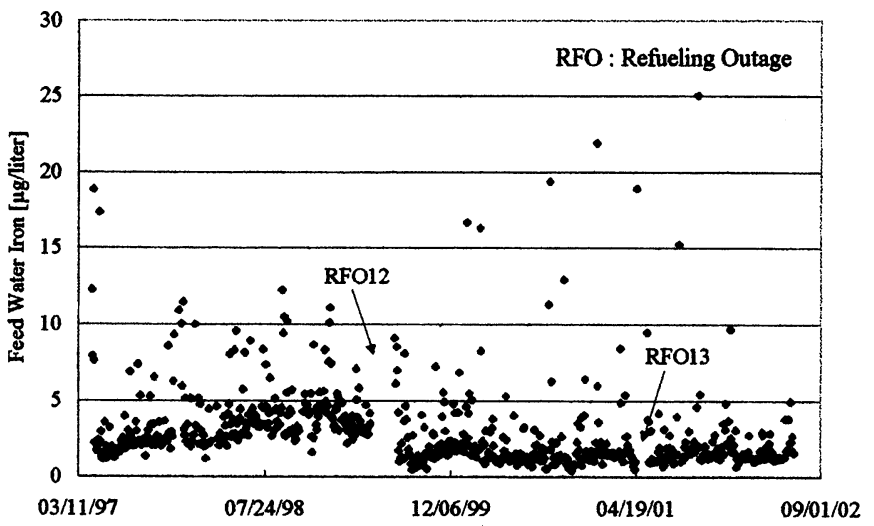

Fig. 2 Feed Water Iron Control at Pilgrim Plant

\section{14\% Cross-linked Cation Gel Resin at BWR plants in Japan}

The 14\% XL cation resin was first installed in condensate polishers at two BWR plants in Japan in May and July 2001. Those plants had experienced sulfate increases up to $10 \mu \mathrm{g} / \mathrm{dm}^{3}$ with the $8 \% \mathrm{XL}$ cation gel resin as a result of gradual oxidation. As shown in Fig. 3 and 4, after the replacement with the $14 \% \mathrm{XL}$ cation gel resins, the reactor water sulfate immediately began to decrease and continued to less than $1 \mu \mathrm{g} / \mathrm{dm}^{3}$. Although the highest condensate temperature in the summer of 2002 was around $45^{\circ} \mathrm{C}$, the sulfate in the reactor water in both plants stayed below $1 \mu \mathrm{g} / \mathrm{dm}^{3}$.

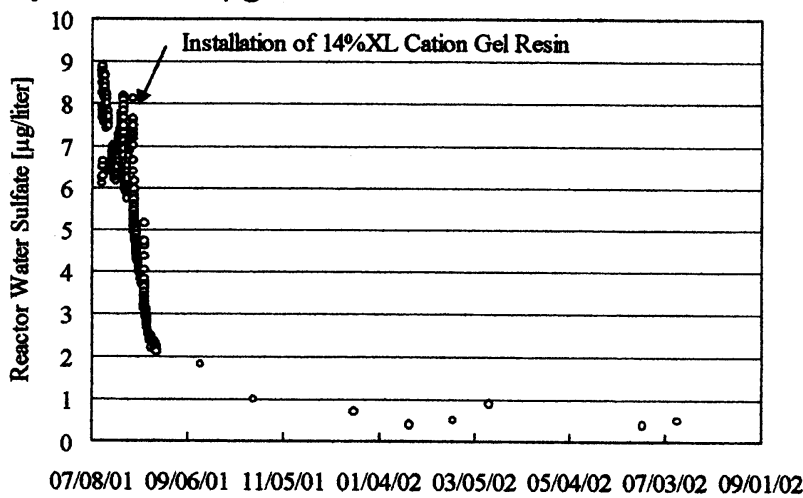

Fig. 3 Reactor Water Sulfate Control at Plant A

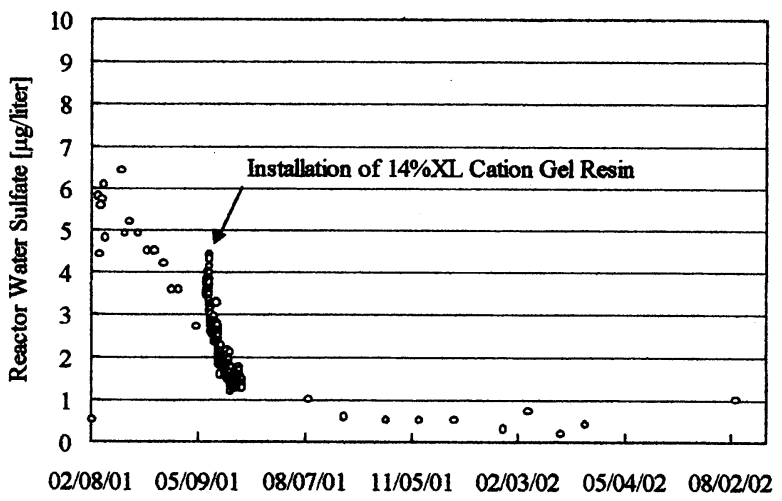

Fig. 4 Reactor Water Sulfate Control at Plant B

\section{References}

1) S.W.Najmy, Official Proceedings of International Water Conference, 62, pp.15-26 (2001)

2) T.Izumi, M.Hagiwara, T.Ino, T.Takai, M.H.Tegen, M.Endo, N.Bessho, The $63^{\text {rd }}$ Annual Meeting International Water Conference, IWC-02-06 (2002) 